\title{
PERANCANGAN SISTEM PENDETEKSI JARINGAN SELULER DI BAWAH JARINGAN TEGANGGAN TINGGI SUTET BERBASIS IoT
}

\author{
Kemal Farouq Mauladi ${ }^{1}$, Nurul Fuad ${ }^{2}$, Affan Bachri ${ }^{3}$ \\ 1) Program Studi Teknik Informatika, Fakultas Teknik, Universitas Islam Lamongan \\ ${ }^{2)}$ Program Studi Teknik Elektro, Fakultas Teknik Universitas Islam Lamongan \\ ${ }^{3)}$ Dosen Program Studi Teknik Informatika, Fakultas Teknik, Universitas Islam Lamongan \\ ${ }^{4)}$ Dosen Program Studi Teknik Elektro, Fakultas Teknik, Universitas Islam Lamongan \\ kemalfarouq@unisla.ac.id ${ }^{l)}$ nurulfuad@unisla.ac.id ${ }^{2}$ affanbachri@unisla.ac.id ${ }^{3)}$
}

\begin{abstract}
Internet Of Things (IoT) Is A Concept Where Internet Connectivity Can Exchange Information With Each Other With Things Around It. Many Predict That the Internet of Things (IoT) is "The Next Big Thing" in the World of Information Technology. System Testing Is Done In The Graha Indah District Of Lamongan Regency. Sensor Nodes Will Be Placed Near High Teget Sutet Network, Atmega 828 Microcontroller in this study as NodeMCU to be able to read data from sensors and convert the data obtained into the form of numbers that are easy to understand. Another function of the program is to send the data to the middleware every 50 seconds. Data retrieval every 60 minutes is intended to be able to get strong and weak GSM network signals that are close to the SUTET electricity network.
\end{abstract} Keywords: Internet Of Things, Atmega 828, Information Technology

\section{Pendahuluan}

Internet of Things (IoT) adalah suatu konsep dimana konektifitas internet dapat bertukar informasi satu sama lainnya dengan benda-benda yang ada disekelilingnya. Banyak yang memprediksi bahwa Internet of Things (IoT) merupakan "the next big thing" di dunia teknologi informasi. Hal ini dikarenakan banyak sekali potensi yang yst dikembangkan dengan teknologi Internet of Things (IoT) tersebut. Teknologi Internet of Things (IoT) diibaratkan dimana alat-alat fisik yst terkoneksi dengan internet. Misalnya, Kulkas, TV, Mesin Cuci dan lainnya dapat di ystem menggunakan smartphone untuk mematikan, menghidupkan dan kegiatan lainnya. Bisa dibayangkan, dengan Internet of Things (IoT) akan lebih mempermudah kegiatan manusia dalam melakukan berbagai aktifitas seharihari. Semua kegiatan dapat dilakukan dengan sangat praktis dan disatu sisi adanya ystem ystem karena perangkat yang terhubung menyebabkan kehidupan akan lebih efektif dan efisien.

Perbedaan jenis dan kebutuhan aplikasi dalam ystem Internet of Things (IoT), membutuhkan jenis sensor yang berbeda-beda, dengan tujuan utamanya adalah untuk mengumpulkan data-data dari lingkungan eksternal yang dibutuhkan. Tujuan utama sensor adalah untuk mengumpulkan data-data dari lingkungan sekitarnya. Sensor, atau yang sering disebut "things" dalam ystem IoT, membentuk ujung depan (front end) dari system. Dalam penelitian ini sistem pendeteksian jaringan seluler yang berada di bawah teganggan tinggi SUTET.

\section{Dasar Teori}

\subsection{Internet of Things}

Internet of things pada dasarnya menghubungkan semua perangkat yang memiliki tombol on dan off ke internet. Perangkat yang dimaksud bisa berupa telepon genggam, mesin penggiling kopi, mesin cuci, lampu, jam tangan pintar, dan hampir semua barang yang dapat dibayangkan. Bagian dari sebuah sistem juga dapat dikendalikan, seperti pintu pada rumah, bor pada mesin pengebor minyak. Istilah Internet of Things sering disebut sebagai teknologi masa kini, yaitu teknologi yang memanfaatkan perangkat komputer berukuran mini dan dapat terhubung dengan jaringan lokal ataupun internet. Perangkat yang digunakan didesain untuk menggunakan daya yang kecil, sehingga perangkat tersebut hanya bisa menjalankan perintah - perintah sederhana. Internet of Things sudah banyak diaplikasikan pada Smart Home saat ini. Perangkat ini diatur untuk melakukan tugas-tugas tertentu saja seperti layaknya sistem yang tertanam untuk membaca data dari sensor. Internet of Things juga dapat digunakan.

\subsection{An Embedded System Model for Air Quality Monitoring}

Jangid menawarkan sebuah rancangan sistem embedded untuk memantau kualitas udara (Jangid, 2016). Dalam rancangannya, Jangid menggunakan Arduino yang memiliki processor Atmega328. Sensor yang ditempelkan pada Arduino ada tiga macam, yaitu MQ-7, DHT-22, dan Sharp GP2Y1010AU0F. Untuk masalah komunikasinya, Arduino dipasangkan dengan modul GSM sebagai wireless modem agar dapat menjangkau jaringan internet. Pada perancangan sistem ini, Arduino juga 
akan dilengkapi dengan sebuah layar untuk melihat data hasil pembacaan oleh sensor. Apabila data yang dibaca sensor melebihi batas tresshold, maka Arduino akan mengirimkan pesan SMS kepada pengguna. Kemudian pengguna akan membaca dan membalas sms tersebut dengan perintah khusus. Di sini Jangid menggunakan Air purifier dan dehumidifier sebagai aktuator. Pengguna mengirimkan pesan perintah khusus yang nantinya akan dapat menyalakan atau mematikan Air purifier dan dehumidifier.

\subsection{Middleware}

Anwari mengatakan bahwa Internet of Things merupakan perpaduan antara internet dan ubiquitos computing. IoT melibatkan interaksi antara beragam perangkat seperti sensor, Anwari mengatakan bahwa Internet of Things merupakan perpaduan antara internet dan ubiquitos computing. IoT melibatkan interaksi antara beragam perangkat seperti sensor, gregator, aktuator dan aplikasi dalam berbagai macam domain. Pada dasarnya IoT terdiri dari dua komponen utama yakni internet dan things. Internet merupakan gabungan infrastruktur jaringan dalam skala masif dan berkembang dinamis berdasarkan standar dan protokol komunikasi yang mendukung interoperabilitas. Sedangkan things merupakan benda atau perangkat baik konkret maupun virtual yang memiliki identitas, atribut, karakteristik dan dapat berkomunikasi satu sama lain melalui sebuah interface. Salah satu permasalahan utama Internet of Things adalah interoperabilitas.

Middleware yang digunakan merupakan middleware multi-protokol berbasis CoAP dan MQTT. Middleware dikembangkan menggunakan paradigma event-driven dan arsitektur ends-tomiddle oleh (Anwari, 2017). Middleware yang telah dikembangkan oleh Anwari memiliki arsitektur yang terdiri dari tiga bagian, yaitu sensor gateway, service unit, dan application gateway. Arsitektur middleware dijelaskan pada gambar 1 sebagai berikut

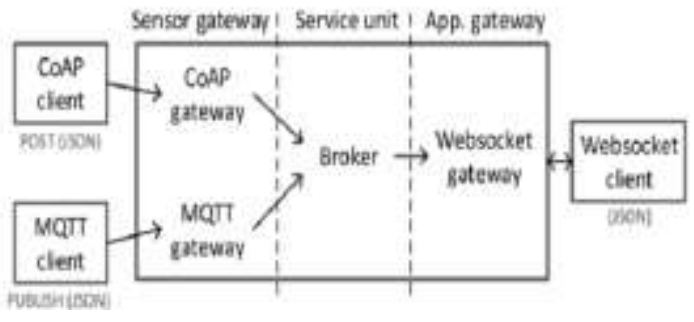

Gambar 1. Arsitektur Middleware

Middleware dijalankan menggunakan raspberry pi 2 model B yang sudah terpasang USB Adapter TL-WN722N - TP-Link sebagai wireless adapter dan dapat dimanfaatkan oleh raspberry pi sebagai access point. Pengiriman data menggunakan pola publish-subscribe. Sensor gateway menyediakan antarmuka bagi sensor untuk mengirimkan data melalui protokol mqtt dan qoap. Service unit berfungsi untuk mengatur topik yang di-subscribe oleh subscriber dan bertanggung jawab mengirimkan data yang diminta oleh subscriber. Application gateway menyediakan antarmuka bagi subscriber untuk meminta topik dan menerima data melalui protokol websocket.

\section{Metode Penelitian}

\subsection{Dasar Teori}

Peneliti akan menggunakan Internet of Things sebagai objek penelitian dengan menggunakan NodeMCU. Dasar teori yang diambil dari referensi ilmiah, jurnal penelitian yang diterbitkan, dan beberapa penelitian yang dilakukan sebelumnya.

\subsection{Perancangan Sistem}

Penelitian ini merupakan eksperiman pengembangan sistem yang terdiri atas hardware dan software. Sistem yang dibuat berupa prototype (miniatur). Tahapan-tahapan penelitian ini adalah sebagai berikut :

a.Identifikasi dan perancangan hardware

Identifikasi untuk mendapatkan kebuthan sistem yang digunakan untuk rancangan hardware. Rancangan hardware berupa rangkaian sensor, indikator dan mikrokontroler yang terhubung ke modul wireless. Dari hardware tetrsebut nantinya akan diimplementasi dengan komponen atau modul yang diperlukan.

b.Implementasi Program

Implementasi program didasarkan pada objek penelitian. Mekanisme tersebut dituanggkan dalam diagram alir dan selanjutnya diimplementasikan dalam bentuk Program.

c.Testing Software

Pengujian dilakukan pada bagian hardware untuk memastikan sensor dapat bekerja pendeteksian jaringan seluler dibawah jaringan teganggan tinggi SUTET. Setelah hardware bekerja dengan baik dan program dibuat, selanjutnya dilakukan pengujian sistem.

Sistem pemantau ini terdiri atas perangkat keras (Hardware) dan perangkat lunak (Software). Hardware berupa mikrokontroler atmega 828 sebagai pengujian sistem kedalam software. Software merupakan program yang akan menjalankan fungsional sistem sehingga data dapat terbaca hingga dikirimkan ke Internet dengan pendekatan IoT

Internet of Things (IoT) pada dasarnya menghubungkan semua perangkat ke internet, IoT sering disebut teknologi masa kini yaitu teknologi yang memanfaatkan perangkat komputer berukuran mini dan dapat terhubung ke jaringan lokal atau internet, perangkat yang digunakan didesain untuk menggunakan daya yang kecil sehingga perangkat tersebut hanya bisa menjalankan perintah - perintah 
sederhana, IoT sudah banyak diaplikasikan pada smart home saat ini, perangkat itu diatur menggunakan tugas-tugas tertentu saja seperti layaknya sistem yang tertanam untuk membaca data dari sensor, IoT juga bisa digunakan sebagai perangkat perantara antara sensor dengan pengguna dan dapat berperan juga untuk mengontrol aktuator.

IoT juga membutuhkan platform layanan yang mempermudah penggunaanya, diantaranya adalah Blynk. Blynk adalah platform baru yang memungkinkan pengguna untuk dengan cepat membangun interface untuk mengendalikan dan memantau hardware dari handphone. Penggunaan Blynk pada dasarnya untuk menghemat waktu dan biaya dalam coding pembuatan aplikasi android penunjang IoT.

Berdasarkan identifikasi pada bagian-bagian perangkat, yang sudah dilakukan dengan mikrokontroler dan perangkat handphone dalam pengujian sistem dengan indikator led warna hijau, kuning, merah sebagai pengontrol sistemnya. Pada penelitian ini dengan handphone type asus dan sistem informasi yang digunakan dengan PHP versi CodeIgniter.

\section{Hasil Dan Pembahasan \\ 4.1 Pengujian dan Analisis}

Pengujian ystem dilakukan di daerah Graha Indah Kabupaten Lamongan. Node sensor akan diletakkan di dekat jaringan SUTET teganggan tinggi. Node sensor akan dinyalakan dan dibiarkan selama 30 menit untuk memanaskan sensor guna mendapatkan hasil pembacaan sensor kedalam ystem. Setelah 60 menit, node sensor akan mulai mengirim data ke middleware setiap 50 detik sekali. Pada pengujian, disediakan middleware yang telah dikembangkan sebelumnya. Data dari middleware akan diteruskan ke data center untuk di simpan didalam database ystem. Data yang disimpan kedalam database akan dikirmkan ke perangkat pengguna berupa smartphone yang memiliki akses ke jaringan. Pada pengiriman data dari sensor ke middleware, akan diuji kinerja ystem berdasarkan Quality of Service

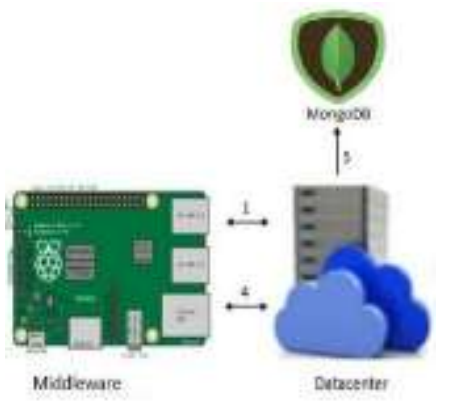

Gambar 4 Proses Alur Sistem

\subsection{Sistem Sensor Atmega}

Mikrokontroler Atmega 828 dalam penelitian ini sebagai NodeMCU untuk dapat membaca data dari sensor dan mengonversi data yang didapat kedalam bentuk angka yang mudah dimengerti. Fungsi program lainnya yaitu untuk mengirimkan data tersebut ke middleware setiap 50 detik sekali. Rogram yang dibuat juga memerintahkan NodeMCU untuk mengambil data waktu terlebih dahulu dari server lokal, dalam hal ini adalah middleware. Data waktu dari server digunakan oleh NodeMCU untuk menginisialisasi waktu pengiriman data sensor berdasarkan waktu pada middleware. Berikut merupakan alur program node sensor.

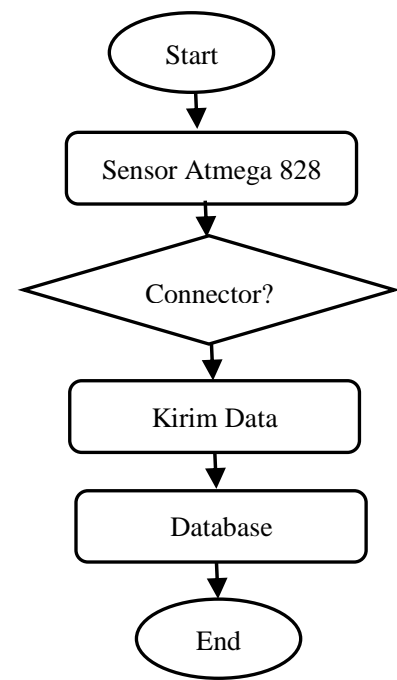

\section{Implementasi}

Gambar 2 Alur Flowchart Sistem

\subsection{Proses Komunikasi Data}

Pengambilan data dilakukan untuk mendapatkan data yang masuk ke dalam data center yang kemudian akan di proses dan disimpan kedalam database sistem. Pada aplikasi nantinya pengguna dapat melakukan request kepada data center guna melihat berapa kuat sinyal jaringan seluler yang ada dalam smartphone masing-masing type jaringan GSM. Proses pengujian sistem dilakukan pada waktu malam hari dan pagi hari dimana sinyal jaringan dipegaruhui oleh arus listrik yang ada di wilayah Graha Indah Lamongan. 


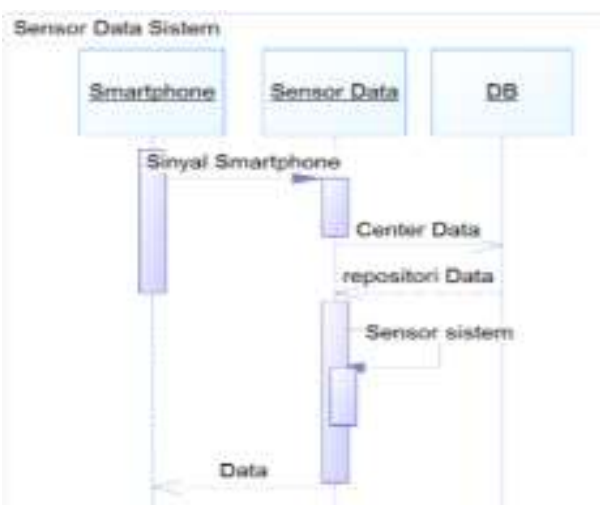

\section{Gambar 5 Proses Komunikasi Data}

\subsection{Fungsi Pengambilan Data}

Pengambilan data setiap 60 menit ditujukan agar dapat mendapatkan kuat lemahnya sinyal jaringan GSM yang dekat dengan jaringan teganggan listrik SUTET. Aplikasi dalam melakukan request kepada data center agar dikirimkan data pada tanggal tertentu, maka data center akan melakukan fungsi ini.

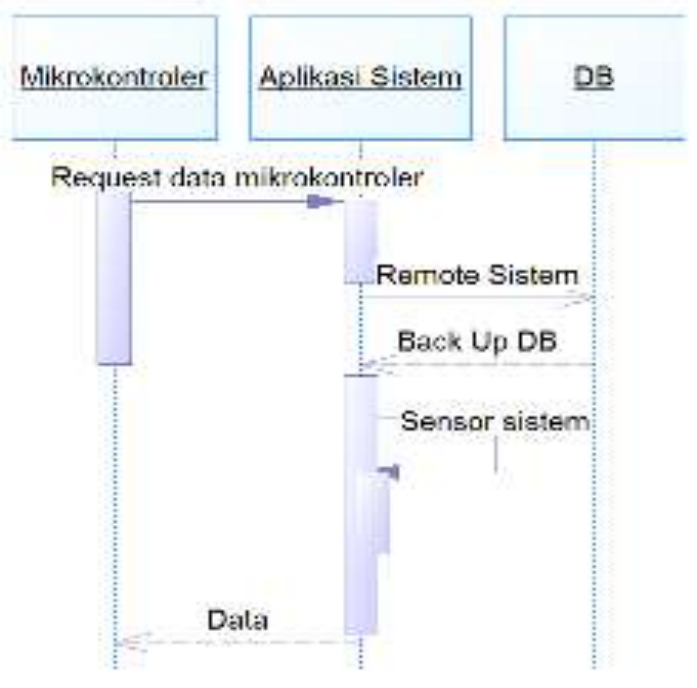

Gambar 6 Proses Pengambilan Data

\subsection{Pengujian Integritas}

Pengujian integritas dilakukan untuk mengetahui apakah aplikasi sesuai dengan kebutuhan fungsional. Pengujian integritas merupakan black box testing yang dilakukan untuk menguji dua atau lebih komponen dari sistem untuk menjalankan satu fungsi tertentu. Pada pengujian ini akan digunakan tools yang akan melakukan pengujian ini secara otomatis. Pengujian dikatakan berhasil jika tidak ada hasil pengujian yang menunjukkan kesalahan. Kemudian untuk pengujian pada sistem yang sudah dirancang, dilakukan dengan menggunakan logging pada saat melakukan run debug pada sistem tersebut.

\subsection{Pengujian Sinyal Smartphone}

Penelitian ini dilakukan dengan cara mngukur kekuatan sinyal Hp menggunakan aplikasi Open signal yang dioperasikan pada smartphone tipe samsung J2 dan menggunakan operator GSM. Adapun yang dites adalah besarnya download (Mbps), Upload (Mbps). Dengan menggunakan utilitas ini, dapat diuji apakah sebuah komputer terhubung dengan komputer lainnya. Hal ini dilakukan dengan cara mengirim sebuah paket kepada alamat IP yang hendak diujicoba konektivitasnya dan menunggu respon darinya.

Kecepatan Download (31,67 Mbps) dan kecepatan upload (1.16 Mbps) juga terjadi pada kondisi pagi hari. Sehingga dapat disimpulkan bahwa kecepatan (kekuatan sinyal) sangat dipengaruhi dengan waktu pengambilan data, mengingat diwaktu-waktu tertentu jaringan (terafik) kadang longgar dan kadang penuh (sibuk). Proses tersebut bisa dilihat pada gambar 7 dibawah ini.

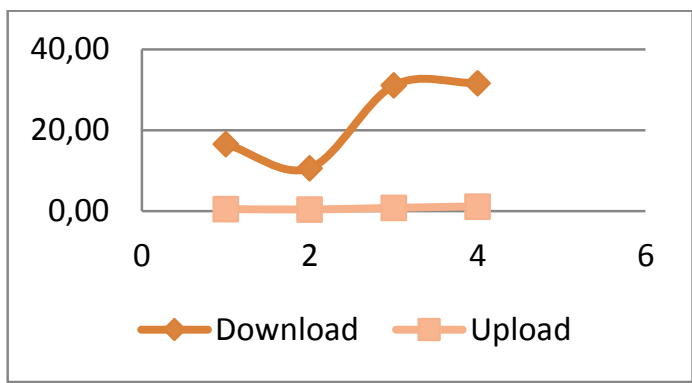

\section{Gambar 7 Grafik Kecepatan download dan Upload berdasarkan waktu}

\section{Kesimpulan}

\subsection{Simpulan}

Berdasarkan pengujian beserta hasil analisis terhadap data uji didapat beberapa kesimpulan, berikut adalah kesimpulan yang dapat diambil, yaitu sebagai berikut:

1. Integrasi node sensor,, dengan IoT middleware sebagai gateway antara cc sensor dengan data center dapat terlaksana dengan menghubungkan node sensor dan IoT middleware menggunakan jaringan Wi-Fi hasilnya tidak ada pengaruh yang signifikan akan kelamahan sinyal GSM pada samrtphone

2. Pengolahan data dari sensor dengan atmega 828 sebagai model data dari node sensor selanjutnya dijadikan patokan dalam pembuatan program untuk melihat tinggal rendah sinyal smartphone yang dekat dengan saluran teganggan tinggi SUTET.

3. Berdasarkan hasil pengujian dapat disimpulkan bahwa sistem yang dikembangkan memiliki nilai rata - rata kecepatan download 31,67 Mbps sedangkan kecepatan upload 1.16 Mbps dalam proses ini terdapat perbedaan waktu antara malam hari dengan pagi hari karena pada waktu 
malam hari proses dowload ataupun upload lebih lama karena jaringan seluler terpengaruh arus teganggan listrik

\subsection{Saran}

1. Pada penelitian berikutnya untuk lebih menggunakan analisis data kuesioner agar mengetahui berbagai macam operator GSM terhadap kekuatan sinyal pada smartphone

2. Untuk peneliti berikutnya aplikasi bisa mencoba sistem android agar lebih cepat untuk memperoleh hasil kecepatan download ataupun upload

\section{Referensi}

1. Charith Perera, A. Z. (2014). Context Aware Computing for The Internet of Things: A Survey. IEEE COMMUNICATIONS SURVEYS \& TUTORIALS, 16(1), 1-25

2. F. Muchlis dan M. Toifur, "Rancang Bangun Prototype Media Pembelajaran Fisika Berbasis Micro Controller NodeMCU," J. Ris. Dan Kaji. Pendidik. Fis., vol. 4, no. 1, hlm. 12-17, Apr 2017.

3. Jangid, S. (2016). An Embedded System Model for Air Quality. IEEE Conference Publications, 3003 - 3008.

4. Morgan, J. (2014). A Simple Explanation Of 'The Internet Of Things. Retrieved March 2, 2017, fromhttps://www.forbes.com/sites/jaco bmor gan/2014/05/13/simpleexplanation- internet-things-thatanyone-can-understand/

5. jQuery Foundation, "A TouchOptimized Web Framework," [Online]. Available: http://jquerymobile.com. [Diakses 30 Agustus 2019] 